\title{
Developing an Evaluation Tool to Examine Motivational Factors of Non-student Community Partnership Participants
}

\section{Dr. Julia D. Thompson, San Jose State University}

Dr. Julia Thompson directs the EPICS (Engineering Projects In Community Service) affiliate program at San Jose State University (EPICS@ @jsu). Dr. Thompson is currently developing and expanding a servicelearning EPICS program. The program is open to all engineering students, including seniors completing capstone requirements. Her research focuses on the characteristics of successful relationships between engineering service-learning programs and the communities they serve. She is currently developing a motivational instrument that identifies factors of participation among administrators, faculty, and community partners.

\section{Dr. Jinny Rhee, San Jose State University}

Dr. Jinny Rhee is the associate dean of the College of Engineering at San Jose State University. She oversees all aspects of the undergraduate programs in the college. Her research interests include administration of programs supporting student success, in addition to thermal management of heat and power systems. Dr. Rhee received a PhD in mechanical engineering from Stanford University (1995). 


\title{
Developing an evaluation tool to examine motivational factors of non- student community partnership participants
}

\begin{abstract}
Research of engineering community engagement has primarily focused on the experiences and outcomes of students, yet it is often the faculty, administrators, and community partners who have a long-term commitment to the program's success. In this study, we are developing and validating an assessment instrument that combines two previously identified aspects of community engagement programs: participant motivation and the nature of engagement relationships. Participant motivation refers to the reasons people stay engaged in the community engagement experience and can be categorized into: student learning and growth, personal and professional development, and benefits to the community organization. The nature of an engagement relationship is defined as the quality of interactions and interpersonal dynamics within partnerships. It is associated with transactional, cooperative, and communal interactions. A validation survey was developed by creating 45 statements associated with the interacting effects of motivational categories and the nature of engagement relationships. Statements were validated by service-learning practitioners with a minimum of two years research and/or practical experience. Validation participants were provided with a codebook for motivational categories and relationship natures. They were asked to code each of the 45 initial statements with the provided categories and natures. We received feedback from eight researchers, with the initial goal of attaining 10 responses. We identified ten statements that maintain at least $75 \%$ coding convergence across responses. Our results highlight key underlying assumptions associated with the TCC Framework and opportunities to improve the instrument to increase clarity and reduce potential bias.
\end{abstract}

\section{Introduction and Literature Review}

Over the last two decades, there has been an increase in the number and extent of engineering service-learning and community engagement programs. Associated research has primarily focused on student learning outcomes [1]. During this time frame, the wider service-learning field has researched partnerships using methods that include analysis of community voice. Building from existing service-learning literature, the authors seek to better understand community-university partnerships in engineering community engagement programs from the perspectives of both the academic program and the served community. This study is developing and validating an instrument examining the motivational factors for non-student participants.

The quality of program relationships and the factors of participant motivations give important insight in understanding and designing programs that are able to meet the needs of the communities and the universities. Bringle and Hatcher [2] developed the StudentOrganization - Faculty - Administrators - Residence (SOFAR) model to highlight five constituent groups and their corresponding relationships. From a motivational standpoint, there are different factors of interest from varied constituent groups. For example, the factors that influence a community organization may be different from those that influence faculty 
and administrators.

In a case study analysis of three engineering community engagement programs, Thompson [3] identified three motivational categories among engineering community partners, faculty, administrators, and students with high levels of engagement. Her findings aligned with similar research of community motivation outside of engineering $[4,5,6]$. These categories of motivation include: student learning and growth; personal and professional responsibility; and benefits to the community organization. Most of the community partners, faculty, and administrators expressed care for student growth and learning. Growth and learning can include professional knowledge, civic engagement, team work, etc. Additionally, many of the non-student participants identified personal learning and professional development as factors for their engagement. Lastly, there was recognition that the community organization received a benefit from their involvement in the partnership.

Nature of a partnership, which is defined as the quality and interpersonal dynamic within a relationship, is understood by the boundary between the different constituent groups. This study bases its evaluation of motivational factors on the Transactional, Cooperative, and Communal Framework [7]. Transactional natures have a heightened boundary of "us" and "them," separating the constituent groups and establishing a dyadic relationship. In cooperative natures, ownership and development of engagement programs is shared, and the lines between "us" and "them" are intentionally blurred as communities and university programs work together. In the communal nature, partnership boundaries are permeable and transcend the participating groups to include the community and/or the society as a whole.

The overarching goal of this study is to develop an evaluation tool that identifies communityspecific motivations and elements of quality improvement for engineering service-learning partnerships. We would like to use this tool to determine motivational factors of various constituent groups, track changes of motivation over time, and compare different universities and programs. To create the tool, we used evidence-based metrics based on key supporting statements reviewed by experienced service-learning practitioners to expand categories of motivation as they interconnect with the nature of relationships. We anticipate that evaluative statements at the intersection of these program components will produce an instrument that can identify participants' motivational influence and quality of service-learning programs. The core research is grounded in engineering community engagement programs. While we intend to pilot the tool in engineering community engagement programs, we would like to expand the instrument to other service-learnings programs. This is considered throughout the instrument's design and validation.

The instrument is intended to support implementation and evaluation of engineering servicelearning programs by clarifying the motivational influences of program participants. For example, the instrument can be given to community partners and instructors to identify their main primary motivations for involvement. Hypothetically, the results suggests that the primary reason the community partner is engaged is to build networks within the community and the primary reason that the faculty member is engaged is to support the students engineering outcomes. The service-learning program administrator can then use this information to make sure that the partner name is recognized in any publications about the 
program, and that the project is meeting engineering rigor requirements. Additionally, there can be discussion with all parties to understand each other's objectives. Overall, this tool can help identify intended programmatic outcomes, establish consistency in language, support the growth of service-learning and establish instructional buy-in. When there is common understanding and language of desired outcomes by constituent groups, it can make program design and implementation less complicated.

After the tool is developed, our aim is to generate a Program Motivation Map of non-student community engagement participants at an accredited, undergraduate engineering servicelearning program in the Western United States. We anticipate that this will provide insight in the program structure and the varying motivational factors amongst participant groups, while identifying opportunities to improve application of educational and social contribution. From there, we would like to expand to include other institutions and non-engineering programs.

\section{Methods}

The aim of this study was to develop evidence-based content for an evaluation tool that identifies motivational factors of non-student participants to engage in engineering servicelearning programs. Ideally, the final product will include a 27 -statement survey tool, with 3 statements for each combination of nature and motivational category. The intended purpose of the instrument will provide an understating of the motivations of engagement of non-student partnership participants. The researchers decided on 27 in order to provide distribution of Natures and Categories ( 9 in each), and not be too overwhelming in terms of length. They will be asked to rank each influence on a 5-point Likert Scale. For example, a participant will be given a statement such as "Students are learning core technical knowledge". Based on that statement, the non-student participant will rank its contribution to their experience using 1-5, with 1 being "irrelevant" and 5 being "highly relevant". The tool then can be used to assess participants motivation before partnerships to better clarify and align expectations, and to identify any motivational changes over time.

To develop the instrument, we created codebooks of the Nature of Partnerships [7] (Table 1) and the Categories of Motivation [3] (Table 2). For each intersecting nature and category of motivation, we wrote out 5 statements, a total of 45 statements (Table 3 ). To validate the content, each statement was reviewed by experienced service-learning practitioners and /or researchers (someone with at least 4 semesters experience in service- learning partnerships), described as "reviewers." We initially sought out ten reviewers to provide feedback. This was number chosen based on conversations with colleagues who have done validation on similar instruments. The number was large enough to identify potential issues across reviewers.

Each reviewer provided their self-identified affiliation, level of expertise with servicelearning, and if engineering was their pre-dominant field. They were given the abovementioned codebook and the 45 statements in a randomized Qualtrics survey. Initially, the study targeted researchers primarily involved in engineering service-learning programs. However, due to the broad pool of expertise in the wider service-learning community, the survey link was also distributed to two service-learning listservs - one focused on SJSU Service-Learning faculty, and a higher education service-learning listserv. 
For evaluation of the responses, we calculated the percentage of convergence amongst the reviewers, with the intention to identify the top three statement prompts with at least $75 \%$ for each interacting category. The seventy-five percent threshold was created through discussion with researchers who had experience of test validation.

Since this research focused on the instrument development, rather than individuals' experience, it did not go through the IRB process.

Table 1: Codebook on the Nature of Partnerships

\begin{tabular}{|c|l|}
\hline \multirow{2}{*}{ Transactional } & $\begin{array}{l}\text { Distinct boundary between stakeholders, thereby tending to preserve or } \\
\text { enhance a sense of "us" and "them" between the participant groups.[7,8,9] }\end{array}$ \\
\cline { 2 - 3 } & $\begin{array}{l}\text { Example: Students are described as doing a project for the community in exchange } \\
\text { for an educational experience }\end{array}$ \\
\hline Cooperative & $\begin{array}{l}\text { Ownership and development of an engagement programs is shared, and the } \\
\text { lines between "us" and "them" are intentionally blurred as communities and } \\
\text { university programs work together. [8,9] }\end{array}$ \\
\hline $\begin{array}{l}\text { Example: Students are described as working together with a community partner on a } \\
\text { single team for the non-profit organization }\end{array}$ \\
\hline \multirow{2}{*}{ Communal } & $\begin{array}{l}\text { Partnership boundaries are permeable and transcend the participating } \\
\text { groups to include the community and/or the society as a whole. [7] }\end{array}$ \\
\hline $\begin{array}{l}\text { Example: Students, community partner, and residents are coming together to } \\
\text { address an issue that is important to the whole community. }\end{array}$ \\
\hline
\end{tabular}

Table 2: Codebook on Categories of Motivation [7]

\begin{tabular}{|c|l|}
\hline & Description \\
\hline \multirow{5}{*}{ Student Learning \& Growth } & $\begin{array}{l}\text { The learning, personal development, and experience solely of the of university } \\
\text { students who are enrolled in the credit-bearing course }\end{array}$ \\
\cline { 2 - 3 } Personal \& Professional Development & $\begin{array}{l}\text { Exple: It is important to me that students learn concepts and skills from the } \\
\text { course }\end{array}$ \\
\hline \multirow{3}{*}{ Community Organization } & $\begin{array}{l}\text { The personal and professional benefits that are gained by the individual (i.e. } \\
\text { the faculty members \&community partners) through the participation in the } \\
\text { community engagement programs }\end{array}$ \\
\cline { 2 - 3 } & $\begin{array}{l}\text { Example: I am a faculty member and personally enjoy teaching this course } \\
\text { The organizational benefit that the community receives through the } \\
\text { community engagement program }\end{array}$ \\
\cline { 2 - 2 } & $\begin{array}{l}\text { Example: As a director of a non-profit, the student work is valuable to the } \\
\text { organization }\end{array}$ \\
\hline
\end{tabular}


Table 3: Results of statement coding to validate assessment tool content basis $(n=8)$

\begin{tabular}{|c|c|c|c|c|c|c|c|c|}
\hline \multicolumn{9}{|l|}{ Student - Transactional } \\
\hline Students learn core issues of the community organizations & 4[ & 4 & 0 & $50 \%$ & 8 & 0 & \begin{tabular}{l|l}
0 & 1 \\
1 &
\end{tabular} & $100 \%$ \\
\hline Students develop the capacity to work with the community & 4 & 3 & 1 & $50 \%$ & 8 & 0 & 0 & $100 \%$ \\
\hline Students gain experience relevant to professional careers & 6 & 0 & 1 & $86 \%$ & 7 & 0 & 1 & $88 \%$ \\
\hline Students learn core engineering skills & 8 & 0 & 0 & $100 \%$ & 8 & 0 & \begin{tabular}{l|l}
0 & 1 \\
\end{tabular} & $100 \%$ \\
\hline Students work on projects that are needed in the community & \begin{tabular}{l|l}
3 & 0 \\
\end{tabular} & 3 & 2 & $38 \%$ & \begin{tabular}{l|l}
1 & 0 \\
\end{tabular} & \begin{tabular}{l|l}
0 & 0 \\
\end{tabular} & \begin{tabular}{l|l}
7 & 0 \\
\end{tabular} & $88 \%$ \\
\hline \multicolumn{9}{|l|}{ Student - Cooperative } \\
\hline Students learn professional skills (i.e. team building, communication, working on multi-disciplinary teams) & 5 & 3 & 0 & $63 \%$ & 7 & 0 & 1 & $88 \%$ \\
\hline Students are exposed to new learning environments & 7 & 1 & 0 & $88 \%$ & 8 & 0 & \begin{tabular}{l|l} 
& 1 \\
\end{tabular} & $100 \%$ \\
\hline Students cultivate a joy of learning & 6 & 0 & 1 & $86 \%$ & 7 & 1 & 0 & $88 \%$ \\
\hline Students develop self-awareness about their strengths and weaknesses and leaderships skills & 7 & 0 & 0 & $100 \%$ & 8 & 0 & \begin{tabular}{l|l}
0 & 1 \\
\end{tabular} & $100 \%$ \\
\hline Students are introduced to unfamiliar people and places & 6 & 1 & 1 & $75 \%$ & 7 & \begin{tabular}{l|l}
0 \\
\end{tabular} & 1 & $88 \%$ \\
\hline \multicolumn{9}{|l|}{ Student - Communal } \\
\hline Students are exposed to important moral and ethical issues & 5 & 2 & 0 & $71 \%$ & 7 & 0 & 1 & $88 \%$ \\
\hline Students learn that they are a contributing member of a community & 3 & 3 & 2 & $38 \%$ & 8 & 0 & \begin{tabular}{l|l}
0 & 1 \\
\end{tabular} & $100 \%$ \\
\hline The personal transformation of students can lead to societal change & 3 & 1 & 3 & $43 \%$ & 4 & 0 & 4 & $50 \%$ \\
\hline Students are learning to use their professional work for social good & 2 & 5 & 0 & $71 \%$ & 6 & 1 & 1 & $75 \%$ \\
\hline Students are impacting their community as citizens & 1 & 1 & 6 & $75 \%$ & 3 & \begin{tabular}{l|l} 
\\
\end{tabular} & 5 & $63 \%$ \\
\hline \multicolumn{9}{|l|}{ Personal- Transactional } \\
\hline It is part of my professional responsibility to assist in student projects & 4 & 2 & 1 & $57 \%$ & 2 & 5 & 1 & $63 \%$ \\
\hline I am learning valuable professional skills (i.e. communication, team building, project management) & 6 & 1 & 0 & $86 \%$ & 2 & 5 & 1 & $63 \%$ \\
\hline The educational environment results in useful products & 2 & 3 & 3 & $38 \%$ & 2 & 1 & 4 & $57 \%$ \\
\hline I focus on discipline-related parts of the program (e.g. the technical education of engineering) & 6 & 0 & 1 & $86 \%$ & 4 & 2 & 1 & $57 \%$ \\
\hline I want to support the community & 2 & 2 & 4 & $50 \%$ & 1 & $2 \mid$ & 5 & $63 \%$ \\
\hline \multicolumn{9}{|l|}{ Personal- Cooperative } \\
\hline I have made great friendships & 2 & 1 & 4 & $57 \%$ & 0 & 7 & 1 & $88 \%$ \\
\hline I enjoy working in teams & 2 & 5 & 0 & $71 \%$ & 1 & 7 & 0 & $88 \%$ \\
\hline I find it exciting to work with people who think differently than me & 1 & 4 & 3 & $50 \%$ & 1 & 6 & 1 & $75 \%$ \\
\hline I gain personal enjoyment being a mentor and supporting students & 5 & 2 & 0 & $71 \%$ & 0 & 8 & 0 & $100 \%$ \\
\hline It is fun to create a project that benefits the community & $3 \mid$ & 2 & 3 & $38 \%$ & \begin{tabular}{l|l}
0 & 0 \\
\end{tabular} & $4 \mid$ & $4 \mid$ & $50 \%$ \\
\hline \multicolumn{9}{|l|}{ Personal - Communal } \\
\hline I want to contribute to something bigger than myself & 2 & 3 & 2 & $43 \%$ & 1 & 5 & 2 & $63 \%$ \\
\hline I want be a a part of positive change in the community & 2 & 1 & 5 & $63 \%$ & 0 & 3 & 5 & $63 \%$ \\
\hline I enjoy empowering people and community organization(s) a positive impact & 3 & 2 & 3 & $38 \%$ & 0 & 5 & 3 & $63 \%$ \\
\hline I want to gain a deeper sense of purpose with my work & 4 & 1 & 2 & $57 \%$ & 1 & 7 & 0 & $88 \%$ \\
\hline I want to be a contributing member of my community & 1 & $2 \mid$ & 5 & $63 \%$ & \begin{tabular}{l|l}
0 & 0 \\
\end{tabular} & 5 & $2 \mid$ & $71 \%$ \\
\hline \multicolumn{9}{|l|}{ Community Organization - Transactional } \\
\hline The student's work solved a direct need for the community organization & 4 & 2 & 2 & $50 \%$ & 1 & 1 & 5 & $71 \%$ \\
\hline It was the cheapest or easiest way to provide a needed service/product & 7 & 1 & 0 & $88 \%$ & 2 & 1 & 5 & $63 \%$ \\
\hline Students have valuable knowledge and/or skills & 7 & 0 & 0 & $100 \%$ & 4 & 0 & 4 & $50 \%$ \\
\hline The community organization is able to address issues that are aligned with its mission & 2 & 2 & 2 & $33 \%$ & 0 & 0 & 7 & $100 \%$ \\
\hline The work that is completed is needed for the community organization & 5 & $1 \mid$ & 2 & $63 \%$ & \begin{tabular}{l|l}
0 & -1 \\
\end{tabular} & 0 & $8 \mid$ & $100 \%$ \\
\hline \multicolumn{9}{|l|}{ Community Organization - Cooperative } \\
\hline Being involved in the service-learning program provides access to grants and other financial resources & 5 & 2 & 1 & $63 \%$ & 0 & 6 & 2 & $75 \%$ \\
\hline Partnerships allow the community organization to thrive because it brings in new mind sets & 0 & 5 & 3 & $63 \%$ & 0 & 1 & 6 & $86 \%$ \\
\hline Students are the most appropriate group to work on the specific problem & 2 & 2 & 3 & $43 \%$ & 3 & 0 & 5 & $63 \%$ \\
\hline The networks provided by the program supports the community organization in many ways & 1 & 6 & 1 & $75 \%$ & 0 & 0 & 8 & $100 \%$ \\
\hline Building relationships with the community is important for a College/University & 3 & $2 \mid$ & 3 & $38 \%$ & \begin{tabular}{l|l}
0 \\
\end{tabular} & $2 \mid$ & $4 \mid$ & $67 \%$ \\
\hline \multicolumn{9}{|l|}{ Community Organization - Communal } \\
\hline The service-learning partnership provides needed exposure to the community organization & 3 & 3 & 2 & $38 \%$ & 1 & 1 & 5 & $71 \%$ \\
\hline The service-learning program is a part of a larger societal movement & 0 & 0 & 8 & $100 \%$ & 0 & 1 & 7 & $88 \%$ \\
\hline The project will create a significant benefit for our community & 1 & 2 & 5 & $63 \%$ & 0 & 0 & 8 & $100 \%$ \\
\hline Students serve as positive role models for the underserved community & 0 & 7 & 1 & $88 \%$ & 1 & 1 & 6 & $75 \%$ \\
\hline The service-learning program is a part of coalition to make needed changes in the community & 0 & 1 & 7 & $88 \%$ & \begin{tabular}{c|c}
0 & 0 \\
\end{tabular} & 0 & 8 & $100 \%$ \\
\hline
\end{tabular}




\section{Results and Discussion}

Results are based on the input of 8 reviewers who coded the statements (Table 3). Two of the reviewers intentionally did not assign codes to all statements, and left comments explaining their actions. Overall, 10 statements met the seventy-five percent (75\%) convergence threshold for both the nature of relationship and Category of Motivation, and only one statement had complete convergence in the Nature and Category of Motivation. The results do not meet the desired 27 statements quality thresholds. We intend to re-write the statements to meet the threshold. Based on the results, the researchers examined trends and investigated issues regarding the statements, codebook, and method of validation. In this section, we discuss the insights of the statements in terms of clarity and interdependent interactions.

Many of the statements were unclear in terms of participant group and nature. Only one statement had complete convergence. The aligned Student-Transactional statement says, "Students learn core engineering skills." The Nature of this statement is Transactional. It identifies knowledge of a single constituent group, students, and the educational environment aligns with traditional engineering learning outcomes. Other statements had included multiple stakeholders. For example, "students work on projects that are needed in the community." This statement was intended to focus on the students' experience working on a project, rather than focus on the projects within the community. The reviewers had identified multiple natures, and seven of them identified community. Revising the statement as, "Students work on projects," would focus on the students, and the transactional element of the partnership.

The second insight about the statements is the interdependent interactions between the Nature of Partnerships and Category of Motivations. Out of the 10 statements that met the convergence threshold, 6 statements were identified by reviewers as Student-Transactional, 1 was identified as Cooperative-Community Organization, and 3 were identified as CommunalCommunity Organization. This bifurcation of convergence had the researchers re-examine the codes and recognize interdependence of the two categories. The Nature of Partnership is determined based on the boundary between the participant groups - transactional interactions recognize distinct boundary, such as an "us" and "them" relationship, where the Communal interactions intentionally blur these boundaries. The statement, relating to students are more likely to specify the single role of student, and thus create an "us" and "them" dynamic. Conversely, the community organization is more likely to have a blurred identity, as people served, broader community, employees and students may be associated of the organization Cooperative and Communal natures of Partnerships are associated with this participant group.

The statement creators intended for the Student-Transactional, Cooperative, and Communal interactions to focus on various types of educational experiences of the students. Learning core technical skills is an outcome that aligns with the existing boundary of engineering; however, when students are pushed to work within multi-disciplinary teaming environments, and in different settings, the boundary of the us- them can start to dissolve and the learning outcome will change. In the initial design, the researchers intended the latter to be Student-Cooperative, based on the change in outcome. However, based on these results, we believe this was not sufficiently defined in the codebook. In future revisions, this will be clarified to understand differences between Natures. 


\section{Conclusion}

Overall, this study allowed us to validate statements necessary to produce a motivational assessment instrument for non-student participants in engineering service-learning programs. It also provided the opportunity to identify potential biases and underlying assumptions that may influence intended outcomes of the instrument. Based on our results, we will have to go through another round of statement revisions and validation in order to reach a convergence rate of seventy-five percent for 27 final statements ( 3 in each interacting category).

A key concern that arose was the distinction of learning outcomes that arise from differing Natures of interactions. As researchers, instructors, and administrators of service-learning programs, the authors understand that certain knowledge and skills are required in different settings. The initial statements recognized that certain knowledge, such as creating capacity to work with community, requires cooperative interactions. However, when a statement singles out one constituent group, students, suggests a transactional nature.

Going forward with the development of the instrument, we need to start thinking of the category of motivation differently and start thinking of how we can expand the boundary of who is a student. In many of the seed research studies, partners and advisors often saw themselves as learners in the service-learning experience. The motivational categorization initially separated this into student learning versus personal and professional development. However, this may be the expansion of the definition of a learner from "student" to include other constituent groups. In a transactional frame, the specific constituent groups are either "learners" or "educators", but as we go into cooperative and communal frames, those boundaries become more permeable, and the "learner" and "educator" becomes less distinct, as the students, instructors, community partners, and community participants occupy multiple roles. 


\section{Reference}

[1] A. Bielefeldt, K. Paterson, and C. Swan "Measuring the impacts of project based service learning." Paper presented at the American Society of Engineering Education, Austin, TX, June, 2009

[2] R.G. Bringle, \& J. Hatcher, "Campus-community partnerships: The terms of engagement.” Journal of Social Issues, vol 58 ED-3, pp. 503-516. 2002.

[3] J. Thompson "Engineering community engagement partnerships: Investigating motivation, nature, and structure," Doctoral dissertation, Dept Engineering Education, Purdue University, West Lafayette, IN, 2015. Retrieved from ProQuest (3720049). 2

[4] M. Sandy, and B. Holland, "Different worlds and common ground: Community partner perspectives on campus-community partnerships," Michigan Journal of Community Service Learning, vol. 13(1), pp 30-43, 2006

[5] L. Worrall, "Asking the community: A case study of community partner perspectives," Michigan Journal of Community Service Learning, vol. 14(1), pp. 5-17, 2007

[6] R. Stoecker, and E. A. Tryon, The unheard voices. Philadelphia: Temple University Press., 2009.

[7] J. Thompson and B. Jesiek, "Transactional, cooperative, and communal: Relating the structure of engineering engagement programs with the nature of partnerships." Michigan Journal of Community Service Learning, vol. 23(2), pp. 83-99, 2017.

[8] N. W. Feinstein, and D. Meshoulam, "Science for what public? Addressing equity in American science museums and science centers". Journal of Research in Science Teaching," vol. 51(3), pp. 368-394, 2014.

[9] H. Sockett, "Levels of partnership," Metropolitan Universities: An International Forum, vol 8(4), pp. 75-82, 1998.

[10] S. Enos, and Morton, K, "Developing a theory and practice of campuscommunity partnerships" In Building partnerships for service-learning, B. Jacoby, Ed. San Francisco: Jossey-Bass, 2003, pp. 20-41.

[11] L. Vanasupa, L. Schlemer, R. Burton, C. Brogno, G. Hendrix, \& N. MacDougall, "Laying the foundation for transdisciplinary faculty collaborations: Actions for a sustainable future.” Sustainability, vol. 6(5), pp. 2893-2928, 2014. 